\title{
Urinary dysfunctions in local advanced rectal carcinoma: urodynamic features and impact of associated-age diseases
}

\author{
R Sacco ${ }^{*}$, V Orsini, R Romano, F Pata \\ From de Senectute: Age and Health Forum \\ Catanzaro, Italy. 5-7 December 2009
}

\section{Background}

Voiding dysfunctions are common complications after rectal cancer resection, secondary to injury to the autonomic nervous plexus. In locally advanced rectal cancer nervous damage can be necessary in order to obtain curative resection. However, the development of a new surgical technique such as Total Mesorectal Excision, nerve sparing dissection (and about multivisceral resections bladder- sparing operations) and greater understanding of the regional anatomy has improved survival and decreased voiding and sexual dysfunction rates [1].

\section{Material and methods}

Between January and December 2003, 35 patients underwent surgery for colorectal cancer (10 left hemicolectomies 21 anterior resections and 4 abdomino-perineal resections). All patients underwent multichannel urodynamic evaluation. The data collected were: bladder capacity and compliance, sensitivity and contractility, and obstruction outlet.

\section{Results}

Twelve months after surgery, urodynamic alterations were found in 14 patients (40\%); the most frequent patterns were detrusor overactivity (4 pts), vesico-sphincter dyssynergia (5 pts) and neurogenic bladder (2 pts).

However, in six patients (5 of left hemicolectomy group and 1 of Miles' group) obstruction outlet due to benign prostatic hypertrophy was discovered.

\section{Conclusions}

The optimal way to objectively describe urinary dysfunctions is by careful urologic history and urodynamic investigation before and after the operation.
In males over the age of 65 , minimal neural damage during surgery may complicate any pre-existing bladder outlet obstruction from benign prostatic hypertrophy [2].

Laparoscopic rectal resection doesn't adversely affect bladder function, but isn't indicated for local rectal cancer [3]. Bladder dysfunction after colorectal surgery can be avoided by identifying and preserving the pelvic autonomic nerves, according to oncologic radicality in performing total mesorectal excision and, if possible, preferring bladder-sparing surgery respect to pelvectomy [4].

Published: 19 May 2010

\section{References}

1. Calpista A, Lai S, Agostini A, Mancini M, Artibani W: Functional urological complications after colo-rectal cancer surgery. Pelviperineology 2007, 26:38-401

2. Mitsui $T$, Shinno $Y$, Kobayashi S, Matsuura S, Shibata T, Ameda K, Koyanagi T: Persistent vesicourethral dysfunction following radical surgery for rectal carcinoma: urodynamic features and potential abatement with modified sphincterotomy (radical transurethral resection of the prostate). Int J Urol 1998, 5(1):39-43.

3. Asoglu $\mathrm{O}$, Matlim T, Karanlik H, et al: Impact of laparoscopic surgery on bladder and sexual function after total mesorectal excision for rectal cancer. Surg Endosc 2009, 23(2):296-303.

4. Winter DC, Walsh R, Lee G, Kiely D, O'Riordain MG, O'Sullivan GC: Local involvement of the urinary bladder in primary colorectal cancer: outcome with en-bloc resection. Ann Surg Oncol. 2007, 14(1):69-73.

doi:10.1186/1471-2318-10-S1-A32

Cite this article as: Sacco et al:: Urinary dysfunctions in local advanced rectal carcinoma: urodynamic features and impact of associated-age diseases. BMC Geriatrics 2010 10(Suppl 1):A32.

General Surgery, "Magna Graecia" University, Catanzaro, Italy 